\title{
Anchoring effects of trait range in impression formation*
}

\author{
DAVID D. SIMPSON, THOMAS M. OSTROM \\ and LLOYD R. SLOAN $\dagger$ \\ Ohio State University, Columbus, Ohio 43210
}

Moderately polarized test traits imbedded in a narrow affective range of context trait adjectives were rated as more extreme than when they were imbedded within a wider range of context traits. It was concluded that the reference scale underlying impression ratings is not impervious to context-related anchoring effects. The implications of this finding for between-Ss tests of Anderson's averaging model are discussed.

Experiments in psychophysics have established that a $S$ anchors his reference scale by the range of stimuli presented for judgment (e.g., DiLollo, 1964; Tresselt, 1947). If stimuli beyond the S's established range are introduced, the end anchors of the psychological continuum shift, and the original stimuli are consequently placed within a narrower range of the S's judgment scale (Parducci, 1965).

The purpose of the present study was to determine whether impression ratings formed from personality trait stimuli are also affected by the range of stimuli in the series being judged. Although research in psychosocial judgment uniformly confirms the existence of such anchoring effects (e.g., Hunt \& Volkmann, 1937; Ostrom, 1966), there is some reason to suspect that the reference scale underlying impression ratings is so well established that variation in stimulus range would not produce shifts in the reference scale end anchors. This is because the stability of a reference scale is known to increase as the number of judgments made within that frame of reference increases (Tresselt, 1947, 1948). Since impression judgments are probably made and shared with others more often than any other form of social judgment, they may thereby have acquired resistance to context-related anchoring effects.

\section{METHOD \\ General Design}

Context trait range (wide and narrow) and valence of test traits (moderately favorable and moderately unfavorable) were varied in a 2 by 2 factorial design, with context a between-Ss factor and valence a within-Ss factor. Ss' impression ratings of persons possessing the traits were assessed on an 8-category favorability rating scale. It was predicted that moderately polarized test traits (those common to both range conditions) when imbedded within a narrow affective range of context traits would be given more extreme ratings than when they were imbedded within a wider range of context traits.

Procedure

Thirty-two students in introductory psychology at Ohio State

*This research was supported by National Science Foundation Grant GN 534.1. Facilities for data analysis were provided by the Computer Center at Ohio State University. Requests for reprints should be directed to Thomas $M$. Ostrom, Social Psychology, 404C West 17th Avenue, Columbus, Ohio 43210.

+Now at the University of Notre Dame.
University participated in the experiment (in four groups of eight each) as partial fulfillment of a research-participation requirement. Stimulus materials were presented in booklet format, and Ss were told that they would be presented a series of adjectives, one to a page, and that they were to think of a person as being described by each of the single adjectives. Immediately beneath each personality trait was an 8-category rating scele, ranging from highly (considerably, moderately, slightly) unfavorable to (slightly, moderately, considerably) highly favorable, on which Ss were to indicate their liking for the stimulus person. Each $S$ made 26 ratings, and the entire task required about $15 \mathrm{~min}$.

\section{Independent Variable}

All 44 traits used in the experiment ( 8 test traits that were common to both context conditions and a separate set of 18 traits for each of the context conditions) were selected from Edwards's (1967) rescaling for Ohio State undergraduates of Anderson's (1968) list. In selecting the test traits, four moderately favorable $(\bar{X}=5.0)$ and four moderately unfavorable $(\vec{X}=3.0)$ traits were chosen.

Context traits for the narrow-range condition were selected with the following distributions: six from scale value 3.0, three from 3.5, three from 4.5 , and six from 5.0. In similar manner, context traits for the wide-range condition were distributed as follows: six from 1.5, three from 2.0, three from 6.0 , and six from 6.5. The mean scale value of traits for both conditions was identical $(\bar{X}=4.0)$ and affectively neutral.

Twelve randomly ordered context traits formed the first part of the booklets in each of the wide-range and narrow-range booklets. Four random orders of the remaining 14 traits (6 context and 8 test) were then generated for the wide-range and narrow-range conditions. Thus, there were four different between-S orders of the second half of the booklet for each condition.

\section{RESULTS}

If Ss use width of context range to anchor the ends of their reference scales in impression formation, traits imbedded in a narrow range of context traits will be rated as more extreme than when the same test traits are imbedded in a wider range context. A repeated measures analysis was performed on the ratings of the eight test traits after computing for each $\mathrm{S}$ his average rating of the four moderately favorable traits and his average rating of the four moderately unfavorable traits. The ratings were converted to numerical scores ranging from 1 (highly unfavorable) to 8 (highly favorable). The Context by Valence interaction was found to be significant $(\mathrm{F}=$ $8.61, \mathrm{df}=1,24, \mathrm{p}<.007)$, indicating that context range did affect the person impression reference scale in a manner similar to the findings obtained with other social stimuli. The mean ratings of the moderately favorable and moderately unfavorable test traits for the wide range and narrow range conditions are presented in Table 1 . Both the favorable and unfavorable test traits received more polarized ratings when they were in the narrower context, reflecting a difference in the unit of the Ss" reference scale (Upshaw, 1969) between the two context conditions. No effect was observed between the conditions, however, on reference scale origin $(F<1)$. 
Table 1

Mean Ratings of Favorable and Unfavorable Test Traits as a Function of Context Width

\begin{tabular}{ccc} 
& \multicolumn{2}{c}{ Test } \\
\cline { 2 - 3 } Context & $\begin{array}{c}\text { Moderately } \\
\text { Width }\end{array}$ & $\begin{array}{c}\text { Moderately } \\
\text { Fnfavorable }\end{array}$ \\
\hline Narrow & 3.50 & 5.95 \\
Wide & 3.83 & 5.45 \\
\hline
\end{tabular}

Note-Ratings were made on a scale from 1 (highly unfavorable) to 8 (highly favorable).

Further analyses demonstrated that the anchoring effect was fairly robust over test traits. The mean difference reported in Table 1 occurred for three out of four of the moderately favorable test traits (curious, softspoken, talkative; but not for frank) and for three out of four of the moderately unfavorable test traits (moody, demanding, frustrated; but not for stubborn). The strength of the anchoring effect did not differ significantly across the four random orders of trait presentation $(\mathrm{F}=1.58, \mathrm{df}=3.24, \mathrm{p}<.22)$.

\section{DISCUSSION}

Little is known about which social reference scales are labile and which are relatively impervious to context effects. The present study found that the reference scale underlying impression judgments, a judgmental scale that is used with great frequency by most people, is systematically affected by context range. It may be, then, that even if differences exist between social reference scales, the least labile will still show context effects.

Knowing that impression ratings are susceptible to context effects helps explain findings recently obtained in a study by Caldwell. ${ }^{1}$ Studies that have rescaled the Anderson (1968) personality traits confirm that Anderson's trait set contains examples of both extremely favorable and extremely unfavorable traits (Essex ${ }^{1}$; Edwards, 1967). However, this was not true in Caldwell's normative scaling study. Words that were placed in the lowest rating category for Anderson (e.g., conceited, unkind, spiteful) were displaced to the second and third rating categories for Caldwell. This shift can be explained by noting that Caldwell includes slang words among those presented for judgment. The lowest rating category came to be anchored by such slang terms as cocksucker, mother fucker, and shit. This finding indicates that the Anderson set of traits only appeared to represent the extremes of the personimpression continuum, because Ss in Anderson's normative scaling task allowed the context range to anchor their reference scale.

The impression formation task has been used extensively in testing Anderson's averaging model of information integration (Anderson, 1971). The present study shows that the averaging model is unable to deal with all the variables that influence impression judgments, since it is unable to make predictions in the present experiment (since neither scale value nor weight were varied). The averaging model operates only at the level of subjective response. Principles of reference scale formation, such as have been proposed by Ostrom \& Upshaw (1968) and Parducci (1965), are needed to explain how the subjective response becomes an overt response.

Sloan \& Ostrom (in press) have shown that a similar distinction must be made in evaluating the averaging model's ability to account for set size effects when obtained in a between-Ss design. Since any between-Ss's design allows for the possibility of different reference scales being formed in different conditions, it appears that the averaging model can only be unequivocally tested in a within-Ss design. This would appear to improve a serious limitation on the explanatory value of the averaging model.

\section{REFERENCES}

Anderson, N. H. Likeableness ratings of 555 personality-trait words. Journal of Personality \& Social Psychology, 1968, 9, 272-279.

Anderson, N. H. Integration theory and attitude change. Psychological Review, 1971, 8, 171-206.

DiLollo, V. Contrast effects in the judgment of lifted weights. Journal of Experimental Psychology, 1964, 68, 383-387.

Edwards, J. D. Revised likeableness ratings of 554 personality trait adjectives. Ohio State University (mimeo), 1967.

Hunt, W. A., \& Volkmann, J. The anchoring of an affective scale. American Journal of Psychology, 1937, 49, 88-93.

Ostrom, T. M. Perspective as a intervening construct in the judgment of attitude statements. Journal of Personality \& Social Psychology, 1966, 3, 135-144.

Ostrom, T. M., \& Upshaw, H. S. In A. G. Greenwald, T. C Brock, and T. M. Ostrom (Eds.), Psychological foundations of attitudes. New York: Academic Press, 1968.

Parducci, A. Category judgment: A range frequency model. Psychological Review, 1965, 72, 407-418.

Sloan, L. R., \& Ostrom, T. M. Amount of information and interpersonal judgment. Journal of Personality \& Social Psychology, in press.

Tresselt, M. E. The influence of amount of practice upon the formation of a scale of judgment. Journal of Experimental Psychology, 1947, 37, 251-260.

Tresselt, M. E. The effect of contrasted groups upon the formation of a new scale judgment. Journal of Social Psychology, 1948, 27, 209-216.

Upshaw, H. S. The personal reference scale: An approach to social judgment. In L. Berkowitz (Ed.), Advances in experimental social psychology. Vol. IV. New York: Academic Press, 1969.

\section{NOTE}

1. The Caldwell and Essex studies are reported in an unpublished mimeographed report by J. Caldwell, D. W. Essex, and T. M. Ostrom: Likeableness ratings of 102 slang words and 785 synonymic associates used in describing personality impressions.

(Received for publication August 28, 1973.) 